\title{
Terms of the stability for the control valve of the hydraulic impulse drive of vibrating and vibro-impact machines
}

\begin{abstract}
The working process and regularities of the functioning of vibrating and vibro-impact machines based on hydroimpulse drive with a singlestage valve pulser are analyzed. The essential characteristics determining the conditions for the excitation and existence of periodic oscillations of the valve-pulser shut-off valve are determined. Using the criterion of A. Hurwitz, based on the differential equation of motion, the existence of undamped periodic oscillations of the valve-pulser shut-off valve is analytically justified.

Streszczenie. Przeanalizowano działanie i regularność pracy maszyn wibracyjnych oraz maszyn poddawanych wibracjom opartych na napędzie hydro-impulsowym z jednostopniowym zaworem impulsowym. Określono podstawowe cechy wpływające na warunki wzbudzenia oraz wystepowania drgań okresowych zaworu impulsowego. Przy zastosowaniu kryterium A. Hurwitza, opartego na równaniu różniczkowym ruchu, istnienie nietłumionych drgań okresowych zaworu impulsowego jest analitycznie uzasadnione. (Warunki stabilności zaworu sterującego hydraulicznym napędem impulsowym maszyn wibracyjnych oraz maszyn poddawanych wibracjom).
\end{abstract}

Keywords: stability, oscillations, valve pulser, hydraulic impulse.

Słowa kluczowe: stabilność, oscylacje, zawór impulsowy, impuls hydrauliczny.

\section{Introduction}

For realization of the most effective modes vibrating influence on the processed materials and the environment is perspective vibrating (VM) and vibro-impact machines (VIM) with hydroimpulse drive (HID) [1]. The main part of the HID is pressure pulse generator, or valve-pulser (VP) [2], which provides control the operation mode of the vibrating machine.

Experimental data and practice operating of hydraulic components VM and VIM, controlled by valve-pulsators, show, that under certain conditions in dynamic system stable self-oscillation processes are excited. Therefore, it is important in the theoretical and applied aspects explore the conditions of excitation and the existence of selfoscillations. These issues have particular importance when developing rational constructions of hydraulic VM and VIM.

The paper [3] presents the results of the research of pressure and lateral exertion on the piston valve. The obtained results are based on the equation Reynolds and equation Navier-Stokes, are compared with variations in the aspect ratio, cross-sectional area. This research purpose is to justify the use of the equation Reynolds for the analysis operating of the piston valve during cavitation. But application the equation Reynolds and equation NavierStokes does not allow the develop clear analytical criteria for determine the conditions for the work stability of the piston VP.

In work [4] the static and dynamic behavior of the pressure control valve with nonlinear negative characteristics is investigated. This pressure regulating valve has the property of both reducing and increasing the pressure at the outlet and actuated by a solenoid. The presented model and linear analysis explains the negative spring constant force in the low-frequency range. The fluctuations of this pressure control valve are based on the principle excitatory force, but the operation of the VP, constructively based on the principle feedback on pressure. Therefore, the used valve research model [4] is not suitable for the study of work processes VP.

To research [5] the influence of the dynamic characteristics of the control valve, a dynamic mathematical and a simulation models with software were given. Based on modeling, the article [5] analyzes the influence of pressure characteristics and characteristics of buffering, acting on the vehicle characteristics during the switching process. However, the article is absolutely not considered the conditions of existence for different operating modes of the control valve.

The purpose of this work is to increase the development efficiency and HID development, by determining the stability areas operating modes of the control equipment - VP.

To do this need to solve the following problem:

- develop and analyze design HID, based on the singlecascade VP, for the implementation of the most effective vibrating and vibro-impact oscillation modes;

- perform an analysis of the work process and regularity of functioning HID and shut-off element of singlecascade VP;

- determine the regions emergence of excitation and the existence of undisturbed periodic oscillations of the shut-off element VP.

Analysis of the design and operating conditions valvepulsator of the hydroimpulse drive

The principle work this type of HID (fig. 1) consists of periodically connected cavity $A$ hydraulic cylinder 2 and pressure pipeline through VP 1 with drainage hydrolysis. VP 1 opens due to increased pressure in the hydrosystem of the drive to the magnitude $p_{r} \geq p_{1}\left(p_{1}-\right.$ pressure "opening" VP) and closes when the pressure in the cavity $A$ decreases to the level $p_{r} \geq p_{2}\left(p_{2}-\right.$ pressure "closure" VP).

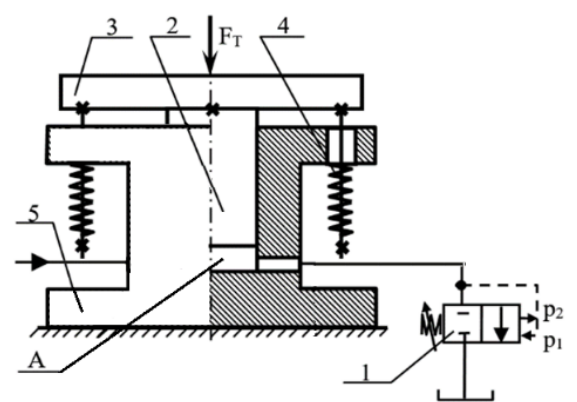

Fig. 1. Typical diagram of the hydroimpulse drive VM and VIM with VP installation "on the output"

The principle work this type of HID (fig. 1) consists of periodically connected cavity $A$ hydraulic cylinder 2 and 
pressure pipeline through VP 1 with drainage hydrolysis. VP 1 opens due to increased pressure in the hydrosystem of the drive to the magnitude $p_{r} \geq p_{1}\left(p_{1}-\right.$ pressure "opening" VP) and closes when the pressure in the cavity $A$ decreases to the level $p_{r} \geq p_{2}\left(p_{2}-\right.$ pressure "closure" VP).

Thus, in the cavity $A$, pulses of pressure with amplitude are generated $\Delta p=p_{1}-p_{2}$. The pressure pulses passage frequency determined by the hydromechanical characteristics of the VP 1 and the supply by hydraulic pump drive. Executive unit 3 vibrates with the pressure pulses passage frequency, and the amplitude of these vibrations depends by the level $p_{1}$, which can be changed by adjusting VP 1 pressure opening, technological force $F_{T}$, frictional forces and total springs forces 4 , which provide together with the technological force $\mathrm{F}_{\mathrm{T}}$ and total weight of forces executive unit 3 (provided it is vertically positioned) returning this unit to its begin position.

The simplest design scheme of a single-cascade VP showing at the fig. 2. This VP consists from shut-off element 1 , in the form of a ball, loaded by the spring 2 , the previous deformation of which can be adjusted by screw 3 . Pressure cavity A joins directly to the hydraulic pump and hydromotor. The intermediate cavity $B$ is separated from the pressure cavity $A$, by the contact locking element of unit 1 along the saddle edge, and from the drain cavity with a positive overlap $z_{\Pi}$.

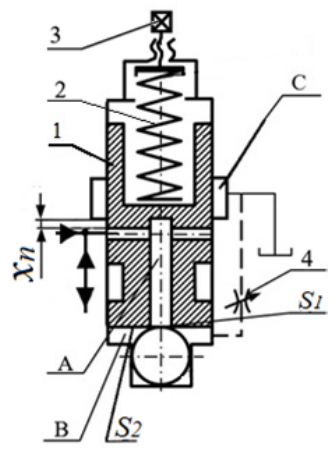

Fig. 2. Valve pulsare

Shutter elements of the distribution units 1 are constructed in such a way, that in the initial position they form two sealing areas $S_{1}$ and $S_{2}$, where $S_{2}>S_{1}$. VP "opening" pressure is determined by the area $S_{2}$ : $\mathrm{p}_{1} \geq \mathrm{cx}_{\mathrm{o} 1} / \mathrm{S}_{1}$, and the "closure" pressure - by area $\mathrm{S}_{2}$ : $\mathrm{p}_{2} \leq \mathrm{c}\left(\mathrm{x}_{\mathrm{o} 1}+\mathrm{x}\right) / \mathrm{S}_{2}$, where $\mathrm{c}, \mathrm{x}_{01}$ - respectively, stiffness and pre-deformation of the spring $2 ; \quad x=x_{\Pi}+x_{B}$ displacement the shut-off element $1 ; X_{B}-$ negative overlapping of unit 1 for a fully open VP.

\section{Analytical substantiation of the existence of non-stop periodic oscillations of the shut-off element VP}

For the analysis of the oscillatory process of the shut-off element VP (fig. 2), we applying the fundamentals of the general theory self-oscillations [4,5], and are developed mainly for generators of electromagnetic oscillations.

To research the dynamics of the working process of this VP (fig. 2), we present its mathematical description under the following basic assumptions: the working fluid pressure at all pressure line volume points and the subclavian cavity A varies in phase; the hydraulic resistance of the pressure and drain lines is small and it can be neglected; the fluid pressure in the drain cavities, as well as in the sub-valvular cavity $\mathrm{B}$, which is connected to them at the opening moment on the drains of the throttle 4 , remains constant and equals some value $P_{z}$; dry friction force is small and it can be neglected; hydraulic pump consumption is constant; compression coefficient of the working fluid is constant; hydrodynamic force that affects the shut-off element of the valve pulser 1 is not taken into account [1].

Based on the principle d'Alembert's the motion equation of the body - shut-off element of the valve-pulsator, at any time can be considered in the form of the following differential equation [15-17]:

$$
\mathrm{m} \frac{\mathrm{d}^{2} \mathrm{x}}{\mathrm{dt}^{2}}=\mathrm{F}_{\mathrm{a}}-\mathrm{F}_{\mathrm{z}}-\mathrm{R}
$$

where $\mathrm{m}$ - mass of shutter element VP; $t$ and $x$ - current time and displacement of moving mass; $F_{a}=p \cdot S_{2}-$ active force influencing on a moving mass from sub-valvular cavity side $A$ and $B\left(p\right.$ - drainage pressure of the working fluid, $S_{2}$ - VP pickup area on the side of the sub-valvular cavity $A$ and $B$ ); $F_{z}=F_{z 0}+c x$ force with which the spring effects on the moving mass $2\left(F_{z 0}-\right.$ force with which the spring 2 effects on the moving mass, c - stiffness of the spring 2 VP); $R=\alpha(d x / d t)-$ the resistance strength, reduced to the force of viscous friction ( $\alpha-$ viscous friction reduced coefficient).

When shutter element 1 moving, the filling and emptying of the sub-valvular cavity $B$ occurs, which can be described by the followed equation continuity flow working fluid:

$$
\frac{\mathrm{d}\left(\mathrm{W}_{\mathrm{h}}-\mathrm{W}_{\mathrm{v}}\right)}{\mathrm{dt}}=\mathrm{Q}_{\mathrm{z}}+\mathrm{Q}_{\mathrm{v}} \text {, }
$$

where: $W_{h}$ i $W_{V}$ - the volumes of liquid submitted by the hydraulic pump and passed through VP for one of its working cycle, respectively; $Q_{z}=(d p / d t) \beta W_{r}-$ working fluid consumption on its compression $\left(\mathrm{W}_{\mathrm{r}}-\right.$ total volume of the hydrosystem, including the volume of the pressure line and sub-valvular cavities $A$ and $B ; \beta$ - volume coefficient of working fluid compression); $Q_{v}=S_{2}(d x / d t)$ - working fluid consumption, which used to move the shut-off element 1. form:

By rewriting the equation (1) and (2) in the following

$$
\begin{aligned}
& \mathrm{m} \frac{\mathrm{d}^{2} \mathrm{x}}{\mathrm{dt}^{2}}+\alpha \frac{\mathrm{dx}}{\mathrm{dt}}+\mathrm{cx}+\mathrm{F}_{\mathrm{z} 0}=\mathrm{pS}_{2} ; \\
& \frac{\mathrm{d}\left(\mathrm{W}_{\mathrm{h}}-\mathrm{W}_{\mathrm{v}}\right)}{\mathrm{dt}}=\frac{\mathrm{dp}}{\mathrm{dt}} \beta \mathrm{W}_{\mathrm{r}}+\mathrm{S}_{2} \frac{\mathrm{dx}}{\mathrm{dt}} .
\end{aligned}
$$

We write the equation (4) relative to the derivative:

$$
\frac{\mathrm{dp}}{\mathrm{dt}}=\frac{1}{\beta \mathrm{W}_{\mathrm{r}}} \frac{\mathrm{d}\left(\mathrm{W}_{\mathrm{h}}-\mathrm{W}_{\mathrm{v}}\right)}{\mathrm{dt}}-\frac{\mathrm{S}_{2}}{\beta \mathrm{W}_{\mathrm{r}}} \frac{\mathrm{dx}}{\mathrm{dt}} .
$$

By differentiate equation (3) with time $t$ and substitute in it equation (5):

(6) $\mathrm{m} \frac{\mathrm{d}^{3} \mathrm{x}}{\mathrm{dt}^{3}}+\alpha \frac{\mathrm{d}^{2} \mathrm{x}}{\mathrm{dt}^{2}}+\left(\mathrm{c}-\frac{\mathrm{S}_{2}}{\beta \mathrm{W}_{\mathrm{r}}}\right) \frac{\mathrm{dx}}{\mathrm{dt}}-\frac{\mathrm{S}_{2}}{\beta \mathrm{W}_{\mathrm{r}}} \frac{\mathrm{d}\left(\mathrm{W}_{\mathrm{h}}-\mathrm{W}_{\mathrm{v}}\right)}{\mathrm{dt}}=0$.

In this equation, the first term characterizes inertia forces changes by time of moving mass, second one friction forces, third - elastic restoring force, and fourth forces of action of the working liquid flowing through the valve pulser.

From equation (6), with consumption working fluid from hydraulic pump and through the valve pulser, i.e. when $Q_{h}=Q_{v}$ or $W_{h}=W_{v}$, shut-off element generate harmonic fading oscillations in accordance with the law $[1,4,8]$ :

$$
\frac{\mathrm{d}^{3} \mathrm{x}}{\mathrm{dt}^{3}}+\frac{\alpha}{\mathrm{m}} \frac{\mathrm{d}^{2} \mathrm{x}}{\mathrm{dt}^{2}}+\frac{\mathrm{c}_{\mathrm{z}}}{\mathrm{m}} \frac{\mathrm{dx}}{\mathrm{dt}}=0
$$


where: $c_{z}=c-\left(S_{2} / \beta W_{r}\right)-$ total stiffness consisting from stiffness of the mechanical spring 2 and stiffness of the hydraulic system unit, which consists of a compressed working fluid in the cavities HID. The ratio of the coefficient friction viscous $\alpha$ to the mass $m$ determines the speed of extinction of oscillations, and $c_{z} / m=\omega-$ the frequency of these oscillations. Such fading oscillations are most common in conventional safety or overflow valves [5,6].

Consider the case when the force of action from the working fluid pressure equals the friction force of the moving masses in the cavities with the housing guiding VP elements $[7,8,17]$ :, then equation $(7)$ becomes a harmonic oscillator equation $[18,19,20]$ :

$$
\frac{\mathrm{d}^{3} \mathrm{x}}{\mathrm{dt}^{3}}+\frac{\mathrm{c}_{\mathrm{z}}}{\mathrm{m}} \frac{\mathrm{dx}}{\mathrm{dt}}=0 .
$$

In this case, the shut-off element of the valve pulser will perform non-stop oscillations with frequency $\omega=c_{z} / m$.

As is known, nonlinear equations of the form (6) do not have regular solving methods [21,22]. However, there are well-known methods of qualitative and quantitative estimation of transients that allow us to study transitional regimes without solving differential equations. For example, for studying the stability of dynamic systems, A. Hurwitz developed criteria on which it is possible to draw conclusions about their stability or instability, based on the coefficients for the terms of equations [10-12].

Exploring equation (6) for a case where the volume of fluid flowing through the vavle pulser exceeds the volume of fluid supplied during this time by the hydraulic pump, ie when $\mathrm{W}_{\mathrm{h}}<\mathrm{W}_{\mathrm{V}}$ or $\mathrm{Qh}<\mathrm{Q}_{\mathrm{V}}$. Moreover, $\mathrm{Qh}<\left[\mathrm{Q}_{\mathrm{V}}\right]$, where $\left[\mathrm{Q}_{\mathrm{V}}\right]$ the marginal consumption that can pass through the valve pulser through itself, providing on the confluenting the pressure of the working fluid that does not exceed the value p. Taking into account the accepted assumption [13,14]:

$$
\frac{\mathrm{d}\left(\mathrm{W}_{\mathrm{h}}-\mathrm{W}_{\mathrm{v}}\right)}{\mathrm{dt}}=\mathrm{Q}_{\mathrm{h}}-\mathrm{Q}_{\mathrm{v}}=-\Delta \mathrm{Q} \text {. }
$$

We substitute equation (8) into equation (7) and introduce a substitution:

$$
a_{0} \frac{d^{3} x}{d t^{3}}+a_{1} \frac{d^{2} x}{d t^{2}}+a_{2} \frac{d x}{d t}-a_{3}=0
$$

where: $a_{0}=1 ; \quad a_{1}=\alpha / m ; \quad a_{2}=c_{z} / m ; a_{3}=\Delta Q S_{2} / \beta W_{r}$. Since, the coefficients $a_{0}, a_{1}, a_{2}, a_{3}$ positive, then this transition process has oscillatory character $[9,10]$.

Let's write the A. Hurwitz matrix of stability [11]:

$$
\Delta=\left|\begin{array}{ccc}
\mathrm{a}_{1} & \mathrm{a}_{3} & 0 \\
\mathrm{a}_{0} & \mathrm{a}_{2} & 0 \\
0 & \mathrm{a}_{1} & \mathrm{a}_{3}
\end{array}\right| .
$$

Determinants of the main matrix minors (10):

$$
\begin{gathered}
\Delta_{1}=\mathrm{a}_{1}=\frac{\mathrm{c}_{\mathrm{z}}}{\mathrm{m}}>0 ; \Delta_{2}=\mathrm{a}_{1} \mathrm{a}_{2}-\mathrm{a}_{0} \mathrm{a}_{3}=\frac{\alpha \mathrm{c}_{\mathrm{z}}}{\mathrm{m}^{2}}-\frac{\Delta \mathrm{QS}}{\beta \mathrm{W}_{\mathrm{r}}}>0 ; \\
\Delta_{1}=\mathrm{a}_{3}\left(\mathrm{a}_{1} \mathrm{a}_{2}-\mathrm{a}_{0} \mathrm{a}_{3}\right)=\frac{\alpha \mathrm{c}_{\mathrm{z}} \mathrm{S}_{2}}{\beta \mathrm{W}_{\mathrm{r}} \mathrm{m}^{2}}-\frac{\Delta \mathrm{QS}_{2}^{2}}{\beta^{2} \mathrm{~W}_{\mathrm{r}}^{2}}>0 .
\end{gathered}
$$

Let's converted an expression to $\Delta_{2}$ :

$$
\frac{\alpha c_{\mathrm{z}} \beta \mathrm{W}_{\mathrm{r}}-\Delta \mathrm{QS}_{2} \mathrm{~m}^{2}+\mathrm{m}^{2} \beta \mathrm{W}_{\mathrm{r}}}{\mathrm{m}^{2} \beta \mathrm{W}_{\mathrm{r}}}>1 .
$$

Under the condition (11), this dynamic system will have a continuous oscillation process. In case if the flow that comes from the hydraulic pump $Q_{h}$ will exceed consumption $Q_{v}$, which is passed at a given pressure $p$ through $V P$, ie when $Q_{h}>Q_{v}$ or $W_{h}>W_{V}$, as well as in the case where the movement of the shut-off element to the opening of the throttle (increase its passage cross section) is limited and $Q_{v}>\left[Q_{v}\right]$, then the derivative is similar (2) takes look like:

$$
\frac{\mathrm{d}\left(\mathrm{W}_{\mathrm{h}}-\mathrm{W}_{\mathrm{v}}\right)}{\mathrm{dt}}=\mathrm{Q}_{\mathrm{h}}-\mathrm{Q}_{\mathrm{v}}=-\Delta \mathrm{Q} \text {. }
$$

When substituting the value (11) in the differential equation (6) in its characteristic equation, the free term will be negative. Consequently, the transition process in this case will not have oscillatory character, as it is not executed Routh-Hurwitz criterion [11,14,15]. Valve pulser shut-off element will be in stable equilibrium state. Or more precisely, it will be immovably pressed by the liquid work flow force to the all the way, and any of its fluctuations will cease.

Thus, subject to the condition (11), in the dynamic system there will be never-ending periodic oscillations, socalled auto-oscillation. Unlike forced or parametric oscillations, these auto-oscillations not related to the effect of periodic external force or periodic change of system parameters. Auto-oscillations arise at the expense of a nonperiodic energy source - a constant working fluid flow that comes under pressure from the drive hydraulic pump and due to internal connections and interactions in the system itself. One of the important this auto-oscillating system feature can be the presence of the so-called magnitude pressure connection in the hydrosystem, which is spent on overcoming dissipative forces of resistance. In a dynamic system there arises variable force $F$, which supports the periodic reciprocating movement of the VP shut-off element, and which is guided by its motion. Moreover, this variable force $F$ disappears when the movement is stopped.

\section{Graphical interpretation of the working cycle VP}

For more in-depth research of the conditions of excitation and the existence of periodic oscillations VP shutoff element, based on the generalized results of experimental studies [1], a diagram of the working cycle was constructed (fig. 3).

This diagram corresponds to the working cycle of a single-cascade VP (fig. 2). On fig. 3 shows the theoretical curves of functions:

$x=f(t) ; F_{\Sigma}=f_{2}(t) ; F_{H}=f_{3}(t) ; F_{+}=\Psi_{1}(x) ; F_{-}=\Psi_{2}(x)$,

where: $X$ - current coordinate of the VP 1 shut-off element movement; $F_{H}$ - current pressure of the working fluid in the pressure line; $F_{\Sigma}, F_{+}, F_{-}-$accordingly, the resulting, active and dissipative forces acting on the shut-off element of the valve pulser. In addition, Figure 3 is also marked: $\Delta \mathrm{E}-$ tributary of energy entering the oscillating dynamic system; $P_{\max }, P_{\min }, P_{0}, P_{\Sigma \max }, X$ - respectively, the maximum, minimum and drainage working fluid pressure in the hydrosystem, the maximum resulting force acting on the shut-off element, and its maximum displacement; $T$ duration of the working cycle - "opening-closing" of the VP shut-off element; $F_{01}=C \cdot X_{01}$ - force of preliminary tightening of the regulated spring 2 (fig. 2), $C$ and $X_{01}$ - stiffness and magnitude of the previous deformation of the regulated spring 2.

Let's consider the theoretical diagram (fig. 3) the most characteristic points working cycle single-cascade valve pulser. When actuating the driving hydraulic pump, the pressure of the working fluid in the pressure line begins to increase from $P_{0}$ to some explicitly set value $P_{\max }$, defined previous deformation value of the regulated spring 2 . This period is most good seen on the function curve $P_{H}=f_{3}(t)$ 
(points " $\left.a_{3} "-" b_{3} "\right)$, where it is shown how the resulting force acting on the VP shut-off element 1 changes $\mathrm{F}_{01}=\mathrm{C} \cdot \mathrm{X}_{01}$ from negative to zero. At that single-cascade valve pulser shutoff element is fixed (points " $a_{1} "-" b_{1}$ " on the function curve $X=f(t)$ and there is an increase in active force $F_{+}, v$ (points "a"-"b" on the function curv $F_{+}=\Psi_{1}(x)$ ). Next, when the resultant force $F_{z}$, acting on the VP shut-off element 1 , will receive a positive value, it will begin to rise upward relative to the initial position. As a result, the throttle gap $x_{B}$, which is formed by a VP shut-off element 1 , and a positive overlap $x_{n}$ decreases to zero (curve $X=f(t)$ (points $" b_{1} "-" v_{1}$ " on fig. 3 ).

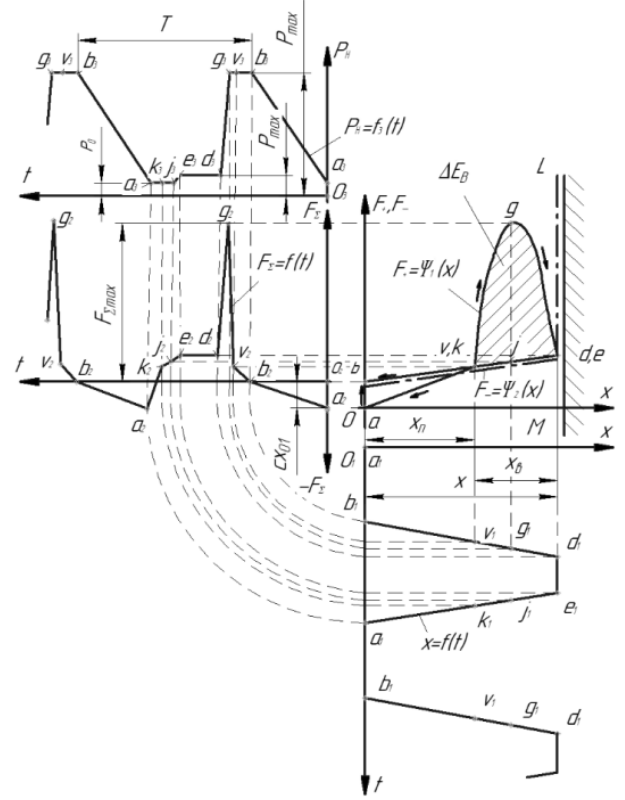

Fig. 3. VP working cycle theoretical diagram

After passing the VP shut-off element 1 of the specified point "b1" resultant stress, acting on the end $S_{2}$ VP shut-off element 1 , sharply increases (on the plot " $\mathrm{v}_{2} "-" \mathrm{~g}_{2}$ " graphic $F_{\Sigma}=f_{2}(t)$ jump-like change is shown). In addition, on the curve of the active force function $F_{+}=\Psi_{1}(x)$, points on the plot "v"-"g" reflect the similar nature of the active force change $F_{+}$. At the moment, active force $F_{+}$substantially exceeds the magnitude of the dissipative force that changes on $F$. and is determined by the magnitude of the counteraction of the elastic force of the VP spring 2, which thus deforms.

At some point " $\mathrm{g}_{1}$ " (function curve $\mathrm{X}=\mathrm{f}(\mathrm{t})$ VP shut-off element 1 passes a constructive overlap $x_{n}$ (fig. 2) and connects the high-pressure subclavian cavity $A$ with the drainage cavity $\mathrm{C}$. This leads to an instantaneous drop in pressure in the pressure line to some value $P_{\min }$, which is determined by the regulation of the throttle 4 (fig. 2). Characteristics of the workflow in this period are displayed on the function curve $P_{H}=f_{3}(t)$, where in the plot " $g_{3} "-" d_{3}$ " shows a drop in the pressure of the working fluid in the pressure line, and on the curve $-\mathrm{F}_{\Sigma}=\mathrm{f}_{2}(\mathrm{t})$ illustrated change - a sharp decrease in the resulting force $F_{\Sigma}$ (plot " $\left.g_{2} "-" d_{2} "\right)$, and on the plot "g"-"d" by the curve $-F_{+}=\Psi_{1}(x)$ also reflected a sharp drop in active force $F_{+}$, which is at the extreme point "d" equals to dissipative force $F=\Psi_{2}(x)$. Because active $F_{+}$and dissipative $F_{\text {. forces are in balance }}$ for some time (points "d"-"e"), then it leads to the passage of some residual liquid volume to the drains, which is accumulated in the pressure line and in the cavities under a certain pressure $P_{\min }$, value of which is determined by the area of the region $S_{2}$ the cross-section of the VP shut-off element 1 and the spring force 2 . During this period the VP shut-off element 1 is immobile (function curve $x=f(t)$, points "d $\left.d_{1}-" e_{1} "\right)$. Resulting force $F_{\Sigma}$ and working fluid pressure in the pressure line $p_{\mathrm{H}}$ at the same time stable (points "d2""e $e_{2}$ and "d $\mathrm{d}_{3} "-\mathrm{e}_{3}$ ").

As soon as the working fluid pressure in the pressure line and subclavian cavity $A$ and $B$ will become lower $P_{\min }$, then under the dissipative force action $F$. the return of the shut-off element to the begin position will occur (points " $e_{1} "-$ " $j_{1} "-" k_{1} "-" a_{1} "$ function curve $x=f(t)$ on figure 3$)$. At the same time active force $F_{+}$falls to zero, and dissipative force $F$. fixes all moving elements in the initial position. The work cycle is completed and then periodically repeated.

It was hypothesized that there is a self-oscillation in this dynamic system of the valve pulser. To analyze this hypothesis, let's dwell on the energy ratios that most fully characterize the oscillation process $[7,10]$. A stable oscillatory process is possible in the case when there is a balance of energy in the system, that is, when the energy coming from the energy supply compensates for the energy expended to overcome the resistance forces. In the absence of balance, the amplitude of the oscillation or increases if there is a flow of energy in the system, or fade, if the filling of losses is insufficient.

The mechanism of self-excited oscillation can be represented as follows. At an initial moment, at small values of the amplitude of oscillations, the flow of energy is greater than its consumption and therefore the amplitude in the system increases. If the ratio of the received energy and the energy expended on the resistance does not change, then the amplitude increases to infinity. Therefore, in order to obtain a stable working process, it is necessary that, from some oscillations value amplitude, the energy loss grew faster than the inflow from the source.

Let's consider our concrete example of auto-oscillating system. On figure 3 shows the curves of active and dissipative forces, respectively $F_{+}=\Psi_{1}(x)$ and $F_{-}=\Psi_{2}(x)$, which graphically illustrate the change in the energy balance this valve pulser dynamical system, depending on the displacement magnitude, relative to the initial position of its VP shut-off element 1. The area under the graph (fig. 3 ), which is limited by the curve $F_{+}=\Psi_{1}(x)$, Characterizes the inflow of energy into the system from the driving hydro pump, and the area is limited by the curve $F=\Psi_{2}(x)$ characterizes its expense to overcome the forces of resistance from the side of the spring 2 , while turning the VP shut-off element 1 (fig. 2). The energy balance takes place at the points of the section of the function curves lines $\mathrm{F}_{+}=\Psi_{1}(\mathrm{x})$ and $\mathrm{F}_{\mathbf{S}}=\Psi_{2}(\mathrm{x})$. In this case, it is possible to conditionally distinguish some points and plots of the dynamic system equilibrium positions. Point "a" (start of coordinates) corresponds to the stationary position equilibrium of the system. Equilibrium position at the point "a" steady, since for small values of the active force value $F_{+}$, which in beginning of the process smaller dimension $F_{01}$ the force of the VP egulating spring 2 previous tightening (fig. 2), the shut-off element of the valve pulser is motionless, that is, resistance energy prevails. Autooscillating dynamic systems, in which the energy of the resistance prevails initially, relate to systems with rigid excitation $[5,7,8]$. The state of the energy equilibrium, in which this system is located on the plot "b"-" $v$ " unstable because at a certain shift of the VP shut-off element 1 the amplitude of the active force $F_{+}$jump-like growing (point "g"). In system, at the same time, the prevails of external energy tributary over the resistance energy and then the amplitude of oscillations - the displacement of the VP shutoff element 1 increases to some stationary value of $X$. In point "d" ("e") by analogy with the point "a" system will be stable. This is explained by the fact that it is near the point "d" ("e") the energy of resistance is prevails, and the 
external force energy $F_{+}$decreases. The energy losses $\Delta \mathrm{E}$ on the implementation of the oscillation process is determined in this case by the area magnitude of the region enclosed between the lines of the curves of functions $F_{+}=\Psi_{1}(x)$ i $F_{-}=\Psi_{2}(x)[9,22-24]$.

Analyzed graphical interpretation (fig. 3) working process of this dynamic system showed that it has another characteristic feature. This feature is that in mechanical systems of this type there is an ambiguity active force in relation to the movement, that is, one value of the shut-off element 1 movement VP corresponds to two values of the active force $\mathrm{F}_{+}$.

The required energy is spent on the oscillatory system only in the ambivalent external force presence. In addition, it should be noted that the presence of double-valued force sees the fundamental difference of the valve pulser from the ordinary. For example, a safety or overflow valve, which has a unique active force, cant supply an energy reserve to excite the shut-off element oscillations.

\section{Conclusions}

1. The design of the HID is developed and analyzed, based on single-cascade VP, for the implementation of the most effective vibrating and vibro-impact modes of oscillations.

2. Analyzed of the working process and the regularity of the HID functioning and shut-off element of singlecascade VP.

3. The most significant characteristics which determine the conditions for the excitation and existence of periodic oscillations of the shut-off element VP are determined:

- fluctuations of the shut-off element VP occur when its construction is equipped with a special additional effective area, which is subject to the sudden action of high pressure of the working fluid and promotes the emergence in the given dynamic system socalled ambivalent active force, which depends on the magnitude of the offset from the initial position;

- non-stop oscillations are provided when the working liquid flow consumption provided by the driving hydro system does not exceed the maximum allowable consumption, which is calculated at a given pressure difference, a specific valve-pulsator;

- a prerequisite for the emergence and existence of an unbreakable oscillation process is compliance with condition (11), as a result of evaluation, according to criteria A;

- an indispensable condition for the existence in this dynamic system of stable self-oscillations is the balance of energy coming from the source - driven hydraulic pump and the energy, that going to compensate the forces of resistance to the displacement of the locking and distributing unit VP.

Authors: Dr. Techn. Sc., Prof., Rostislav D. Iskovych-Lototsky Vinnytsia National Technical University, Department of Industrial Engineering, 95 Khmelnytske shose av., 21021, Vinnytsia, Ukraine, Email: ivanchuck@ukr.net; PhD. Techn. Sc., Prof., Ivan V. Kots, Vinnytsia National Technical University, Department of engineering systems in construction, 95 Khmelnytske shose av., 21021, Vinnytsia, Ukraine, E-mail: ivanchuck@ukr.net; PhD. Techn. Sc., Ass. Prof., Yaroslav V. Ivanchuk, Vinnytsia National Technical University, Department of Industrial Engineering, 95 Khmelnytske shose av., 21021, Vinnytsia, Ukraine, e-mail: ivanchuck@ukr.net; Evheniy I. Ivashko, Engineering, Vinnytsia National Technical University, Department of Industrial Engineering, 95 Khmelnytske shose av. 21021, Vinnytsia, Ukraine, e-mail: ivanchuck@ukr.net; PhD. Konrad Gromaszek, Lublin University of Technology, Institute of Electronics and Information Technology, Nadbystrzycka 38A, 20-618 Lublin, Poland, email: k.gromaszek@pollub.pl; Assel Mussabekova, Kazakh Academy of Transport \& Communication, email: asel 1989 09@mail.ru; Mashat Kalimoldayev, Institute Information and Computational Technologies CS MES RK, email: mnk@ipic.kz.

\section{REFERENCES}

[1] Iskovych-Lototsky R. D., Ivanchuk Y. V., Vibrating and vibro-impact devices for unloading vehicles, UNIVERSUM, 2012

[2] Iskovych-Lototsky R. D., Zelinska O. V., Ivanchuk Y. V., Veselovska N. R., Development of the evaluation model of technological parameters of shaping workpieces from powder materials, Eastern-European Journal of Enterprise Technologies. Engineering technological systems, 1 (2017), n.85, 9-17

[3] Sung-Ho H., Kyung-Woong K., The validity of the Reynolds equation in spool valve analysis considering cavitation, Friction, 4 (2016), n.3, 266-276

[4] Alessandro D., Modelling and experimental validation of a nonlinear proportional solenoid pressure control valve, International Journal of Fluid Power, 17 (2016), 90-101

[5] Feng R., Xinhui L., Jinshi C., Ping Z., Boliang L., Qinmeng W., Dynamic Characteristics Analysis of Power Shift Control Valve, Advances in Mechanical Engineering, 6 (2015), 1-7

[6] Iskovych-Lototsky R. D., Ivanchuk Y. V., Veselovsky Y. P., Simulation of working processes in the pyrolysis plant for waste recycling, Eastern-European Journal of Enterprise Technologies. Energy-saving technologies and equipment, 1 (2016), n.8(79), 1120

[7] Cheng C., Chen Z., Shi H., Liu Z., Xiong Y., System-Level Coupled Modeling of Piezoelectric Vibration Energy Harvesting Systems by Joint Finite Element and Circuit Analysis, Shock and Vibration, (2016), 1-9

[8] Deli W., Wei X., Xudong G., Haiqing P., Response analysis of nonlinear vibro-impact system coupled with viscoelastic force under colored noise excitations, International Journal of Non-Linear Mechanics, 86 (2016), 55-65

[9] Jörg C., Mont K., Pornsak S., Response analysis of nonlinear vibroimpact system coupled with viscoelastic force under colored noise excitations, Chemical Engineering Research and Design, 88 (2010), n.1, 100-108

[10] Vedmitskyi Y. G., Kukharchuk V. V., Hraniak V. F., New nonsystem physical quantities for vibration monitoring of transient processes at hydropower facilities, integral vibratory accelerations, Przeglad Elektrotechniczny, 93 (2017), nr.3, 69-72

[11] Kukharchuk V. V., Kazyv S. S., Bykovsky S. A., Discrete wavelet transformation in spectral analysis of vibration processes at hydropower units, Przeglad Elektrotechniczny, 93 (2017), nr.5, 6568

[12] Kukharchuk V. V., Hraniak V. F., Vedmitskyi Y. G., Bogachuk V. V., etc., Noncontact method of temperature measurement based on the phenomenon of the luminophor temperature decreasing, Proc. SPIE, 10031 (2016)

[13] Kukharchuk V. V., Bogachuk V. V., Hraniak V. F., Wójcik W., Suleimenov B., Karnakova G., Method of magneto-elastic control of mechanic rigidity in assemblies of hydropower units, Proc. SPIE, 10445 (2017)

[14] AllaEl-Marhomya A., Eldin A., Stability analysis of rotor-bearing systems via Routh-Hurwitz criterion, Applied Energy, 77 (2004), n.3, 287-308

[15] Jacob K., Hurwitz stability of weighted diamond polynomials, Systems \& Control Letters, 22 (1994), n.4, 303-312

[16] Azarov O. D., Dudnyk O. V., Kaduk O. V., Smolarz A., Burlibay A., Method of correcting of the tracking ADC with weight redundancy conversion characteristic, Proc. SPIE, 9816 (2015)

[17] Azarov O. D., Murashchenko O. G., Chernyak O. I., Smolarz A., Kashaganova G., Method of glitch reduction in DAC with weight redundancy, Proc. SPIE, 9816 (2015)

[18] Osadchuk V. S., Osadchuk A. V., The magneticreactive effect in transistors for construction transducers of magnetic field, Electronics and Electrical Engineering, Technologija, 3 (2011), n.109, 119-122

[19] Osadchuk V. S., Osadchuk A. V., The microelectronic transducers of pressure with the frequency, Electronics and Electrical Engineering, Technologija, 5 (2012), n.121, 105-108

[20] Vasilevskyi O. M., Advanced mathematical model of measuring the starting torque motors, Technical Electrodynamics, 6 (2013), 76-81.

[21] Pavlov S. V., Kozhemiako V. P., Kolesnik P. F., et al., Physical principles of biomedical optics: monograph, VNTU, 2010

[22] Vassilenko V., Valtchev S., Teixeira J. P., Pavlov S., Energy harvesting: an interesting topic for education programs in engineering specialities, Internet, Education, Science, 2016

[23] Vasilevskyi O. M., Yakovlev M. Y., Kulakov P. I., Spectral method to evaluate the uncertainty of dynamic measurements, Technical Electrodynamics, 4 (2017), 72-78

[24] Voronin A., Ajtchanov B., Partyka J., Aldibekova A., Elemements automatic control of hydrodynamic systems, Informatyka Automatyka Pomiary w Gospodarce i Ochronie Srodowiska, 2 (2013), 35-36 